\title{
On the Impact of the User Terminal Velocity on HSPA Performance in MBMS Multicast Mode
}

\author{
Alessandro Raschellà ${ }^{1}$, Anna Umbert ${ }^{2}$, Giuseppe Araniti ${ }^{1}$, Antonio Iera ${ }^{1}$, Antonella Molinaro ${ }^{1}$ \\ ${ }^{I}$ ARTS Laboratory - Dept. DIMET - University "Mediterranea" of Reggio Calabria \\ Reggio Calabria - 89100, ITALY \\ e_mail:\{alessandro.raschella, araniti, antonio.iera, antonella.molinaro\}@unirc.it; \\ ${ }^{2}$ Signal Theory and Communication Dept., Universitat Politecnica de Catalunya (UPC) \\ Jordi Girona, 1-3, 08034 Barcelona, Spain \\ annau@t.sc.upc.edu
}

\begin{abstract}
Multimedia Broadcast/Multicast Services (MBMS), introduced in Universal Mobile Telecommunication System (UMTS), have the aim to allow transmissions from a single source entity to multiple destinations. From the radio perspective, MBMS foresees both pointto-point (PtP) and point-to-multipoint (PtM) transmission mode, supported by Dedicated, Common, and Shared channels. The High Speed Downlink Packet Access (HSDPA), analyzed in this paper, can guarantee a higher data rate through the introduction of High Speed Downlink Shared Channel (HS-DSCH), thus improving the performance of MBMS transmissions. The aim of this paper is to investigate the impact of the User Equipment (UE) speed on the maximum number of users that the HS-DSCH can support for MBMS applications. In particular, two different mobility profiles are taken into account (Pedestrian and Vehicular) and the obtained results are validated by considering different transmission power levels, cell coverage sizes and bit rates.
\end{abstract}

Index Terms-Multicast; UMTS; MBMS; HSPA; User Mobility

\section{INTRODUCTION}

$\mathrm{I}_{\mathrm{n}}$ the last few years, manifest improvements in mobile terminals and network infrastructures supplies users with innovative and enhanced communication services. Thanks to this evolutionary trend, today Third Generation (3G) cellular wireless networks, such as Universal Mobile Telecommunication System (UMTS), are able to provide videoconference, multimedia streams (i.e. TV on mobile phones), broadband transmission, and file downloading services [1]. The introduction of highlighted applications on the one hand has originated the need to increase the bit rate transmission, whereas, on the other hand, has pushed towards the definition of new policies able to optimize the radio resource utilization. For these reasons two new approaches have been introduced by the Third Generation Partnership Project (3GPP) standardization body: (i) the High Speed Downlink Packet Access (HSDPA) technique [2] and (ii) the Multimedia Broadcast and Multicast Service (MBMS) system [3]. HSDPA, standardized as part of Release 5, extends and improves the performance of pre-existing UMTS protocols granting higher data rates [2]. While, MBMS, introduced in UMTS Release 6 specifications, allows point-to-multipoint (PtM) transmissions, in which the same data is delivered from a single source entity to multiple recipients. MBMS services can utilize over the radio interface both Common (Forward Access Channel, FACH) and Dedicated (Dedicated Channel, DCH) channels, defined by UMTS Release 99, as well as Shared transport channel (High Speed Downlink Shared Channel, HS-DSCH), subsequently introduced by HSDPA Release 5.

Several studies have been conducted to determine the conditions in which the utilization of one channel is more efficient compared to the other ones, in terms of radio resource usage. For instance, it has been demonstrated that when the number of multicast users is low, the use of DCH channels is preferred, otherwise either FACH or HS-DSCH may be utilized depending on the considered scenario and radio network conditions. Extensive studies, which aimed at finding out the Thresholds in terms of "served user number" to switch from dedicated to common or shared channels, are reported in $[4,5]$. From these studies clearly emerges that: (i) DCHs are limited in terms of "consumed power"; (ii) FACH in terms of "maximum bit rate"; (iii) HS-DSCH in terms of "served user number" $[4,5]$.

In this work we center our efforts on HSPA technology with the purpose of introducing more information for a correct determination of the Switching Thresholds. In fact, starting from previous studies [4, 5], in this paper, we further demonstrates that the maximum number of users served by the HS-DSCH (and, as a consequence, also the Switching Thresholds) hardly depends on the User Equipment (UE) speed. In particular, two different mobility models are taken into account: Pedestrian and Vehicular. Results are obtained through an analytical computation performed using MATLAB and a simulator implemented by Simulink.

This paper is organized as follows. Section II provides a brief overview about the MBMS, highlighting the system architecture. In Section III the HS-DSCH transport channel is presented. In Section IV the considered multipath profiles and mobility models are described. Main results obtained by simulation campaigns are the focus of Section V. Finally, in the last section, conclusive remarks are presented.

\section{MBMS ARCHITECTURE}

MBMS allows different kinds of content to be broadcasted across a wide area covered by a cellular network, stimulating 
the development of novel mobile mass-media services. As a complement to the unicast solution, the MBMS architecture makes more efficient use of network resources and capacity through PtM transmissions [3]. For instance, it enables several mobile users to watch the same TV program at the same time, and in the same area, even during peak demand of broadcast services. MBMS is implemented by adding new capabilities to the existing functional entities of the 3GPP architecture, as shown in Figure 1.

SGSN (Serving GPRS Support Node) jointly handles the whole set of users subscribing the same MBMS service, by establishing and maintaining a single connection towards the relevant MBMS data source.

GGSN (Gateway GPRS Support Node) performs message screening, mobility handling, data tunneling, QoS negotiation, and policing. It receives IP multicast traffic from MBMS sources and redirects it towards the proper GTP (GPRS Tunneling Protocol) tunnel.

BM-SC (Broadcast-Multicast Service Centre) authenticates and authorizes the content providers and checks the integrity of the data received from them; determines the QoS degrees for MBMS transmissions and provides MBMS data repetitions to face the problem of data loss.

CBC (Cell Broadcast Centre) may be used to announce MBMS services to the users.

UE (User Equipment), following the activation of MBMS services, is enabled to receive MBMS data without explicit user requests, receives indication of further service availability, allows for the simultaneous reception of MBMS service announcements and data, and supports security functions for MBMS services.

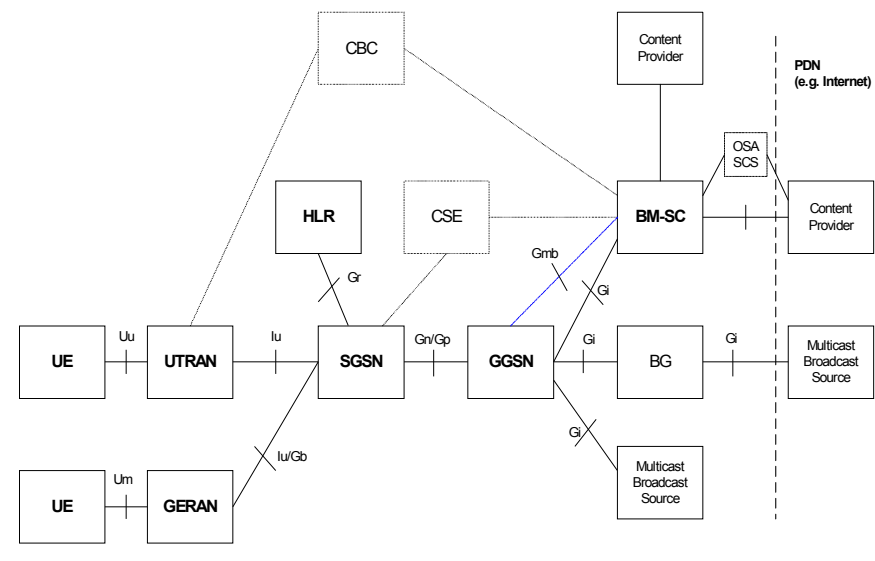

Figure 1 - MBMS architecture [3]

\section{HS-DSCH DESCRIPTION}

HS-DSCH is the shared transport channel introduced by the HSDPA standard to carry out user data in the downlink direction. The main purpose of HSDPA is to increase packet data throughput and rate, by exploiting link adaptation and fast physical layer retransmission. Furthermore, in HSDPA technique the Adaptive Modulation and Coding (AMC) replaces the variable Spreading Factor $(S F)$ and fast power control procedures. The $A M C$ allows changing the kind of modulation and coding depending on the radio channel conditions; the Channel Quality Information (CQI) is a typical
HSDPA parameter that contains such information. In fact, the transport block size, the number of used physical channels and the modulation technique can be evaluated from the CQI value [2].

In a wireless network scenario, the chosen $E_{b} / N_{0}$ corresponds to a particular Block Error Rate (BLER) for a given data rate. However, the $E_{b} / N_{0}$ metric is not an appropriate measure for HSDPA because the bit rate on the HS-DSCH can be varied every Transmission Time Interval (TTI), by utilizing different modulation schemes, effective code rates, and a given number of physical channel codes. Therefore, in the HS-DSCH environment, the $E_{b} / N_{0}$ is replaced by Signal to Interference Noise Ratio (SINR) that represents a more appropriate measurement metric. Equation (1) computes this parameter.

$$
S I N R=S F_{16} \frac{P_{H S-D S C H}}{p P_{\text {own }}+P_{\text {other }}+P_{\text {noise }}}
$$

where $P_{H S-D S C H}$ is the HS-DSCH transmission power, $P_{\text {own }}$ is the own cell interference, $P_{\text {other }}$ is the interference from neighbouring cells, $P_{\text {noise }}$ is the Additive White Gaussian Noise $(A W G N), p$ is the orthogonality factor (that can be zero in the case of perfect orthogonality), and finally $S F_{16}$ is the SF equal to 16. A further useful parameter that has to be taken into account is the geometry factor, defined according to the following Equation:

$$
G=\frac{P_{o w n}}{P_{\text {other }}+P_{\text {noise }}}
$$

Such a parameter indicates the distance from the base station; in fact, a lower $G$-factor is expected when a user is near the cell edge, where the interference from the neighboring cells is higher than the own cell interference. Finally, by rearranging Equation (1) and taking into account Equation (2), we can express the average HS-DSCH SINR as:

$$
S I N R=S F_{16} \frac{P_{H S-D S C H}}{P_{o w n}} \frac{1}{p+G^{-1}}
$$

SINR represents an important parameter for our study because, as it will be explained in the next sections, it influences the CQI that can be chosen and, as a consequence, the number of served users through HS-DSCH.

\section{Mobility Models AND Propagation CHANNEL}

To determine the maximum number of users that can be served by HS-DSCH channels depending on the UE speed, different multipath propagation models used for HSDPA shall be taken into account. In Table 1 such models are summarized, according to what reported in 3GPP standards [6].

As shown in Table 1, there exist two different environments: pedestrian and vehicular. For each environment, a channel impulse response model based on the delayed tap is given. The taps represent the multiple 
reflections of the transmitted signal [7]. Such two environments are characterized by: (i) the number of taps; (ii) the Relative Delay (RD) with respect to the first tap; (iii) the Relative Mean Power (RMP) with respect to the first tap. In [7] it has been demonstrated, through an exhaustive measurement campaign, that generally (case A in the Table), the $R M P$ of a delayed tap is relatively small, but occasionally (case $\mathrm{B}$ in the Table), there are situations (characterized by worst multipath) that lead to a much larger $R M P$ [7]. Therefore, two multipath channels are defined for each environment: (i) ITU Environment A, characterized by low values of $R M P$ (case that occurs frequently), (ii) ITU Environment $\mathrm{B}$ characterized by a larger RMP (case that occurs rarely).

TABle 1: Propagation Conditions For Multi-Path Fading ENVIRONMENTS FOR HSDPA PERFORMANCE REQUIREMENTS [6]

\begin{tabular}{|c|c|c|c|c|c|c|c|c|}
\hline \multirow[b]{4}{*}{$\begin{array}{l}\text { Tap } \\
\text { Number }\end{array}$} & \multicolumn{2}{|c|}{$\begin{array}{l}\text { ITU Pedestrian A } \\
\text { Speed 3km/h } \\
\text { (PA3) }\end{array}$} & \multicolumn{2}{|c|}{$\begin{array}{l}\text { ITU Pedestrian B } \\
\text { Speed 3km/h } \\
\text { (PB3) }\end{array}$} & \multicolumn{2}{|c|}{$\begin{array}{l}\text { ITU vehicular A } \\
\text { Speed 30km/h } \\
\text { (VA30) }\end{array}$} & \multicolumn{2}{|c|}{$\begin{array}{l}\text { ITU vehicular A } \\
\text { Speed 120km/h } \\
\text { (VA120) }\end{array}$} \\
\hline & \multicolumn{2}{|c|}{$\begin{array}{c}\text { Speed for Band I, II } \\
\text { III and IV } \\
3 \mathrm{~km} / \mathrm{h} \\
\end{array}$} & \multicolumn{2}{|c|}{\begin{tabular}{|c} 
Speed for Band I, II, \\
III and IV \\
$3 \mathrm{~km} / \mathrm{h}$ \\
\end{tabular}} & \multicolumn{2}{|c|}{$\begin{array}{c}\text { Speed for Band I, II, III } \\
\text { and IV } \\
30 \mathrm{~km} / \mathrm{h}\end{array}$} & \multicolumn{2}{|c|}{$\begin{array}{c}\text { Speed for Band I, } \\
\text { II, III and IV } \\
120 \mathrm{~km} / \mathrm{h} \\
\end{array}$} \\
\hline & \multicolumn{2}{|c|}{$\begin{array}{c}\text { Speed for Band V, } \\
\text { VI } \\
7 \mathrm{~km} / \mathrm{h} \\
\end{array}$} & \multicolumn{2}{|c|}{$\begin{array}{c}\text { Speed for Band V, } \\
\text { VI } \\
7 \mathrm{~km} / \mathrm{h}\end{array}$} & \multicolumn{2}{|c|}{$\begin{array}{l}\text { Speed for Band V, VI } \\
71 \mathrm{~km} / \mathrm{h}\end{array}$} & \multicolumn{2}{|c|}{$\begin{array}{c}\text { Speed for Band V, } \\
\text { VI } \\
282 \mathrm{~km} / \mathrm{h}\end{array}$} \\
\hline & $\begin{array}{c}\text { Relative } \\
\text { Delay } \\
\text { [ns] }\end{array}$ & $\begin{array}{c}\text { Relative } \\
\text { Mean } \\
\text { Power } \\
\text { [dB] }\end{array}$ & $\begin{array}{c}\text { Relative } \\
\text { Delay } \\
\text { [ns] }\end{array}$ & $\begin{array}{c}\text { Relativ } \\
\text { e Mean } \\
\text { Power } \\
\text { [dB] }\end{array}$ & $\begin{array}{c}\text { Relative } \\
\text { Delay } \\
\text { [ns] }\end{array}$ & $\begin{array}{c}\text { Relative } \\
\text { Mean } \\
\text { Power } \\
\text { [dB] }\end{array}$ & $\begin{array}{c}\text { Relative } \\
\text { Delay } \\
\text { [ns] }\end{array}$ & \begin{tabular}{|c} 
Relative \\
Mean \\
Power \\
[dB]
\end{tabular} \\
\hline $1^{\text {st }}$ Tap & 0 & 0 & 0 & 0 & 0 & 0 & 0 & 0 \\
\hline $2^{\text {nd }} T a p$ & 110 & $-9,7$ & 200 & $-0,9$ & 310 & $-1,0$ & 310 & $-1,0$ \\
\hline $3^{\text {rd }} \mathrm{Tap}$ & 190 & $-19,2$ & 800 & $-4,9$ & 710 & $-9,0$ & 710 & $-9,0$ \\
\hline $4^{\text {th }}$ Tap & 410 & $-22,8$ & 1200 & $-8,0$ & 1090 & $-10,0$ & 1090 & $-10,0$ \\
\hline $5^{\text {th }}$ Tap & & & 2300 & $-7,8$ & 1730 & $-15,0$ & 1730 & $-15,0$ \\
\hline $6^{\text {th }}$ Tap & & & 3700 & \begin{tabular}{|l|}
$-23,9$ \\
\end{tabular} & 2510 & $-20,0$ & 2510 & $-20,0$ \\
\hline
\end{tabular}

Simulation campaigns have been conducted by considering only the ITU Pedestrian A and the ITU Vehicular A channels models, as they represent the cases that frequently occur in a real scenario. However, obtained results, reported in the next section, can be easily generalized to the other two cases.

\section{OBTAINED RESULTS}

The aim of the conducted simulation campaign is to demonstrate that the maximum number of users served by the HS-DSCH (and, as a consequence, also the Switching Thresholds) hardly depends on the UE speed. In particular, we evaluate how the UE speed affects the SINR to be guaranteed and then the maximum number of users that the HS-DSCH can support.

The last one is obtained, as showed in the following, by means of the relation that exists among SINR, CQI and the maximum number of users.

Therefore, two different mobility models are taken into account (ITU Pedestrian A and ITU Vehicular A) and the maximum number of users served by the HS-DSCH is evaluated for: (i) different assigned HS-DSCH power values; (ii) several cell coverage sizes; (iii) two bit rate applications, and (iv) UE category 10 [2].

In Table 2 the main simulation assumptions are presented $[6,8]$.
Firstly, as the SINR depends on the assigned HS-DSCH transmission power and on the distance from the base station (in according to Equation 3), in Figure 2 we show the SINRs that have to be guaranteed when varying the cited parameters.

TABLE 2 - SimULATION ASSUMPTIONS

\begin{tabular}{|c|c|}
\hline Parameter & Value \\
\hline Cellular layout & Hexagonal grid \\
\hline Number of neighbouring cells & 18 \\
\hline Site to site distance & $1 \mathrm{Km}$ \\
\hline Cell radius & $350-550 \mathrm{~m}$ \\
\hline Maximum BS Tx power & $20 \mathrm{~W}$ \\
\hline Other BS Tx power & $5 \mathrm{~W}$ \\
\hline Common channel power & $1 \mathrm{~W}$ \\
\hline Propagation model & Okumura Hata \\
\hline Multipath channel & ITU Pedestrian A and ITU \\
& Vehicular A \\
\hline Orthogonality factor & 0,5 \\
\hline BLER target & $10 \%$ \\
\hline Base station antenna gain & $11,5 \mathrm{dBi}$ \\
\hline Thermal noise & $-100 \mathrm{dBm}$ \\
\hline Shadowing & $10 \mathrm{~dB}$ \\
\hline
\end{tabular}

Users are assumed randomly scattered in the cell whose coverage radius sizes can be respectively equal to either $550 \mathrm{~m}$, or $450 \mathrm{~m}$, or $350 \mathrm{~m}$. As expected from Equation (3), the SINR guaranteed at the edges of the considered coverage radius sizes improves when such size decreases and/or the HS-DSCH assigned power increases.

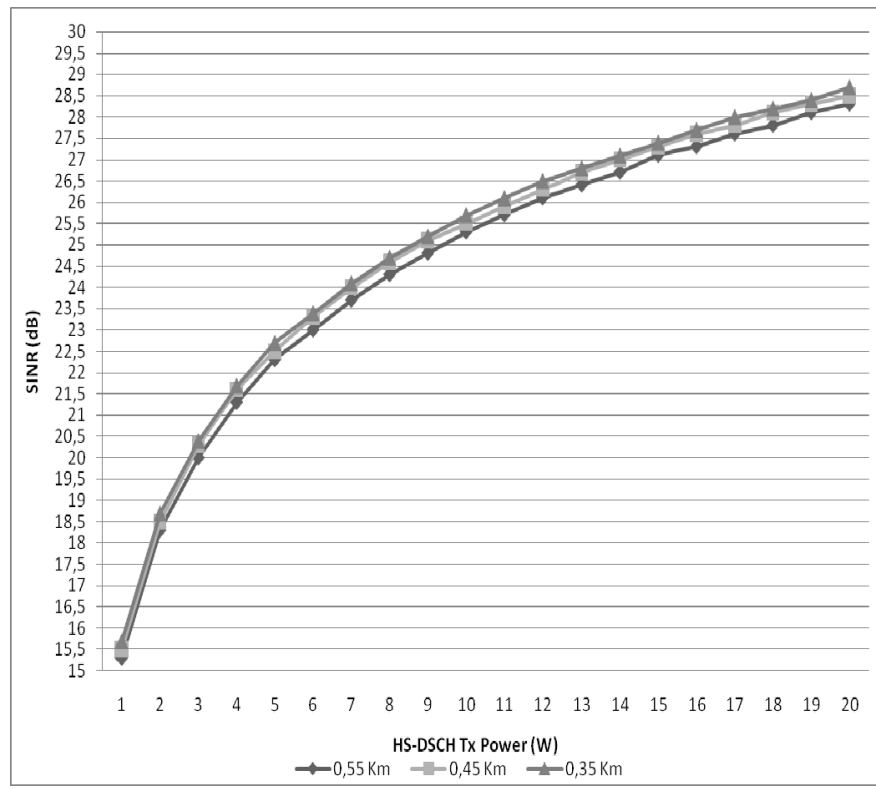

Figure 2 - Guaranteed SINR per Transmission Power and Cell Coverage

Subsequently, we highlight how obtained SINRs limit the maximum number of users served by the HS-DSCH. In fact, in HSDPA, the number of served users depends on the CQI parameters that, in turn, are closely connected to the SINR values.

Therefore, in Figure 3 and Figure 4 we illustrate the SINRs to be guaranteed for different values of CQIs and BLERs, when the mobility models are the ITU Pedestrian $A$ and the ITU Vehicular A respectively.

We obtained such figures through a simulator implemented by Simulink that allowed us to obtain SINR values, when CQI 
and BLER target values are selected. We carried out the simulations by implementing the HS-DSCH coding and modulation chains and the radio channel conditions [10,11]. Such simulated steps are the following: (i) CRC attachment, (ii) Scrambling, (iii) Segmentation, (iv) Turbo Coding, (v) Hybrid ARQ, (vi) Interleaving, (vii) 16QAM constellation rearrangement, (viii) Modulation Mapper, (ix) Scrambling, (x) Modulation, (xi) Multipath depending on the mobility model.

The curves reported in Figure 3 and 4 demonstrate that an increase of the CQI and/or a decrease of the BLER imply higher SINR values to be guaranteed.

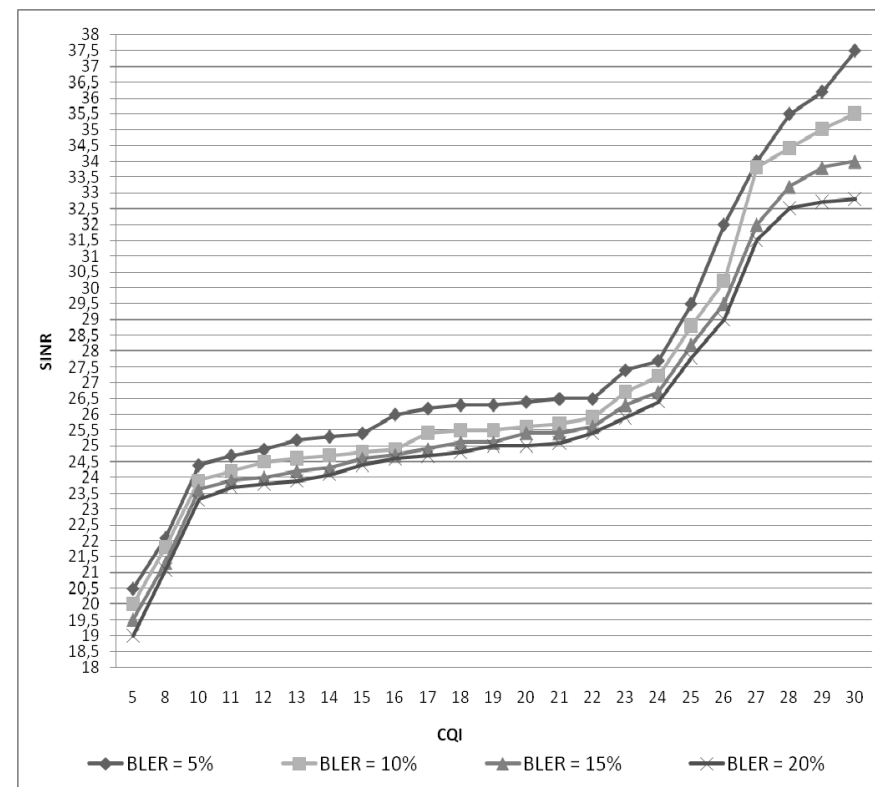

Figure 3 - SINR to be guaranteed per CQI using the ITU Pedestrian A model

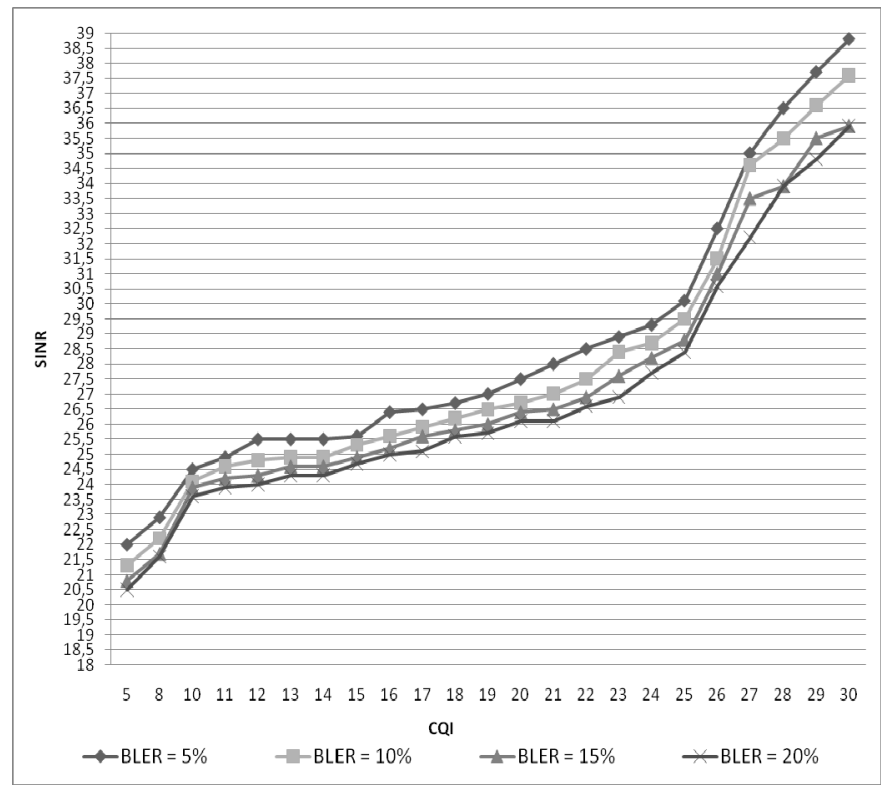

Figure 4 - SINR to be guaranteed per CQI using the ITU Vehicular A model

Moreover, the SINRs are greater utilizing the ITU Vehicular A model compared to the ITU Pedestrian A model. As a consequence, higher UE speeds, when BLER target and
CQI values are set, imply greater SINR values that have to be guaranteed.

Therefore, in Table 3 a mapping between the CQI values and the maximum Physical Bit Rate is illustrated. Every Physical Bit Rate depends on the used modulation technique and on the number of utilized physical channels.

As a consequence, the maximum number of users served by the HS-DSCH is obtained by dividing the maximum Physical Bit Rate by the service bit rate.

For instance, the first CQI value, characterized by a QPSK modulation and by a use of one physical channel, gives a maximum Physical Bit Rate equal to $480 \mathrm{kbps}$ that allows serving 7 UEs for $64 \mathrm{kbps}$ applications and 3 UEs for 128 kbps ones [9].

TABLE 3 - HS-DSCH PARAMETERS

\begin{tabular}{|c|c|c|c|c|c|}
\hline CQI & Modulation & $\begin{array}{l}\text { \# Physical } \\
\text { Channel }\end{array}$ & $\begin{array}{c}\text { Physical } \\
\text { Bit Rate } \\
\text { (kpbs) }\end{array}$ & $\begin{array}{c}\text { UE } \\
\text { Number } \\
\mathbf{6 4} \text { kbps }\end{array}$ & $\begin{array}{l}\text { UE Number } \\
128 \text { kbps }\end{array}$ \\
\hline 1 & QPSK & 1 & 480 & 7 & 3 \\
\hline 2 & QPSK & 1 & 480 & 7 & 3 \\
\hline 3 & QPSK & 1 & 480 & 7 & 3 \\
\hline 4 & QPSK & 1 & 480 & 7 & 3 \\
\hline 5 & QPSK & 1 & 480 & 7 & 3 \\
\hline 6 & QPSK & 1 & 480 & 7 & 3 \\
\hline 7 & QPSK & 2 & 960 & 15 & 7 \\
\hline 8 & QPSK & 2 & 960 & 15 & 7 \\
\hline 9 & QPSK & 2 & 960 & 15 & 7 \\
\hline 10 & QPSK & 3 & 1440 & 22 & 11 \\
\hline 11 & QPSK & 3 & 1440 & 22 & 11 \\
\hline 12 & QPSK & 3 & 1440 & 22 & 11 \\
\hline 13 & QPSK & 4 & 1920 & 30 & 15 \\
\hline 14 & QPSK & 4 & 1920 & 30 & 15 \\
\hline 15 & QPSK & 5 & 2400 & 37 & 18 \\
\hline 16 & 16-QAM & 5 & 4800 & 75 & 37 \\
\hline 17 & 16-QAM & 5 & 4800 & 75 & 37 \\
\hline 18 & 16-QAM & 5 & 4800 & 75 & 37 \\
\hline 19 & 16-QAM & 5 & 4800 & 75 & 37 \\
\hline 20 & 16-QAM & 5 & 4800 & 75 & 37 \\
\hline 21 & 16-QAM & 5 & 4800 & 75 & 37 \\
\hline 22 & 16-QAM & 5 & 4800 & 75 & 37 \\
\hline 23 & 16-QAM & 7 & 6720 & 105 & 52 \\
\hline 24 & 16-QAM & 8 & 7680 & 120 & 60 \\
\hline 25 & 16-QAM & 10 & 9600 & 150 & 75 \\
\hline 26 & 16-QAM & 12 & 11520 & 180 & 90 \\
\hline 27 & 16-QAM & 15 & 14400 & 225 & 112 \\
\hline 28 & 16-QAM & 15 & 14400 & 225 & 112 \\
\hline 29 & 16-QAM & 15 & 14400 & 225 & 112 \\
\hline 30 & 16-QAM & 15 & 14400 & 225 & 112 \\
\hline
\end{tabular}

If, for instance, we can assign $11 \mathrm{~W}$ to the HS-DSCH, when considering 450 meters of radius, then a SINR equal to 25.9 $\mathrm{dB}$ could be guaranteed (see Figure 2). By examining the case when the ITU Pedestrian A is the considered channel model, we can notice that the guaranteed SINR is the value that allows obtaining a CQI equal to 22 when $10 \%$ is the selected BLER target (see Figure 3). This means that the maximum number of users is 75 for applications with a bit rate equal to $64 \mathrm{kbps}$; while it is 37 when such a value is equal to $128 \mathrm{kbps}$ (see Table 3).

Finally, next tables summarize the maximum number of users, obtained when varying cell coverage radius size, transmission power, given a target BLER of $10 \%$. In 
particular, Table 4 refers to the ITU Pedestrian A mobility model, while Table 5 to the ITU Vehicular $A$ model. We assume the values of assigned HS-DSCH transmission power varying between 7 and $12 \mathrm{~W}[5,10]$.

TABLE 4 - MAXIMUM NUMBERS OF USERS FOR ITU PEDESTRIAN A MODEL

\begin{tabular}{|c|c|c|c|c|c|}
\hline $\begin{array}{c}\text { Cell } \\
\text { Coverage } \\
\text { Radius (m) }\end{array}$ & $\begin{array}{c}\text { HS-DSCH } \\
\text { Tx Power } \\
\text { (W) }\end{array}$ & $\begin{array}{c}\text { SINR } \\
\text { (dB) }\end{array}$ & CQI & $\begin{array}{c}\text { UE Number } \\
\mathbf{6 4} \text { kbps }\end{array}$ & $\begin{array}{c}\text { UE Number } \\
\mathbf{1 2 8} \text { kbps }\end{array}$ \\
\hline \multirow{4}{*}{550} & 7 & 23,7 & 10 & 22 & 11 \\
\cline { 2 - 6 } & 8 & 24,3 & 11 & 22 & 11 \\
\cline { 2 - 6 } & 9 & 24,8 & 15 & 37 & 18 \\
\cline { 2 - 6 } & 10 & 25,3 & 17 & 75 & 37 \\
\cline { 2 - 6 } & 11 & 25,7 & 21 & 75 & 37 \\
\hline \multirow{4}{*}{450} & 12 & 26,1 & 22 & 75 & 37 \\
\cline { 2 - 6 } & 7 & 24 & 11 & 22 & 11 \\
\cline { 2 - 6 } & 8 & 24,6 & 13 & 30 & 15 \\
\cline { 2 - 6 } & 9 & 25,1 & 16 & 75 & 37 \\
\cline { 2 - 6 } & 10 & 25,5 & 19 & 75 & 37 \\
\hline \multirow{4}{*}{350} & 11 & 25,9 & 22 & 75 & 37 \\
\cline { 2 - 6 } & 12 & 26,3 & 22 & 75 & 37 \\
\cline { 2 - 6 } & 7 & 24,1 & 11 & 22 & 11 \\
\cline { 2 - 6 } & 8 & 24,7 & 14 & 30 & 37 \\
\cline { 2 - 6 } & 10 & 25,2 & 16 & 75 & 37 \\
\cline { 2 - 6 } & 11 & 26,1 & 22 & 75 & 37 \\
\hline
\end{tabular}

TABLE 5 - MAXIMUM NUMBERS OF USERS FOR ITU VEHICULAR A MODEL

\begin{tabular}{|c|c|c|c|c|c|}
\hline $\begin{array}{c}\text { Cell } \\
\text { Coverage } \\
\text { Radius (m) }\end{array}$ & $\begin{array}{c}\text { HS-DSCH } \\
\text { Tx Power } \\
\text { (W) }\end{array}$ & $\begin{array}{c}\text { SINR } \\
\text { (dB) }\end{array}$ & CQI & $\begin{array}{c}\text { UE Number } \\
\mathbf{6 4} \text { kbps }\end{array}$ & $\begin{array}{c}\text { UE Number } \\
\mathbf{1 2 8} \text { kbps }\end{array}$ \\
\hline \multirow{4}{*}{550} & 7 & 23,7 & 8 & 15 & 7 \\
\cline { 2 - 6 } & 8 & 24,3 & 10 & 22 & 11 \\
\cline { 2 - 6 } & 9 & 24,8 & 12 & 22 & 11 \\
\cline { 2 - 6 } & 10 & 25,3 & 15 & 37 & 18 \\
\cline { 2 - 6 } & 11 & 25,7 & 16 & 75 & 37 \\
\hline \multirow{4}{*}{450} & 12 & 26,1 & 18 & 75 & 37 \\
\cline { 2 - 6 } & 7 & 24 & 10 & 22 & 11 \\
\cline { 2 - 6 } & 8 & 24,6 & 11 & 22 & 11 \\
\cline { 2 - 6 } & 9 & 25,1 & 14 & 30 & 15 \\
\cline { 2 - 6 } & 10 & 25,5 & 16 & 75 & 37 \\
\hline \multirow{4}{*}{350} & 11 & 25,9 & 17 & 75 & 37 \\
\cline { 2 - 6 } & 7 & 26,3 & 18 & 75 & 37 \\
\cline { 2 - 6 } & 8 & 24,1 & 10 & 22 & 11 \\
\cline { 2 - 6 } & 9 & 24,7 & 12 & 22 & 11 \\
\cline { 2 - 6 } & 10 & 25,7 & 16 & 37 & 37 \\
\cline { 2 - 6 } & 11 & 26,1 & 18 & 75 & 37 \\
\hline
\end{tabular}

Figures 5 and 6 are graphical representations of some results shown in the Tables above. They highlight the differences between the mobility models in terms of maximum number of users served by HS-DSCH, for two different cell coverage radius sizes $(550 \mathrm{~m}$ and $350 \mathrm{~m})$. From such figures we can assert that the propagation conditions specified by the ITU Pedestrian A model always allows serving either a greater or an equal number of users in comparison to the ones of the ITU Vehicular $A$ model. Furthermore, it clearly emerges that smaller radius sizes allow serving a larger number of multicast users. It's worth noting that the maximum number of users served by $H S-D S C H$ could be the same also with different CQIs (see Table 3). In these cases, the CQI values are characterized by the same Physical Bit Rate; therefore, to understand the difference among such CQIs, we need to take into account also the Data Rate and the Data Link Bit Rate [11].

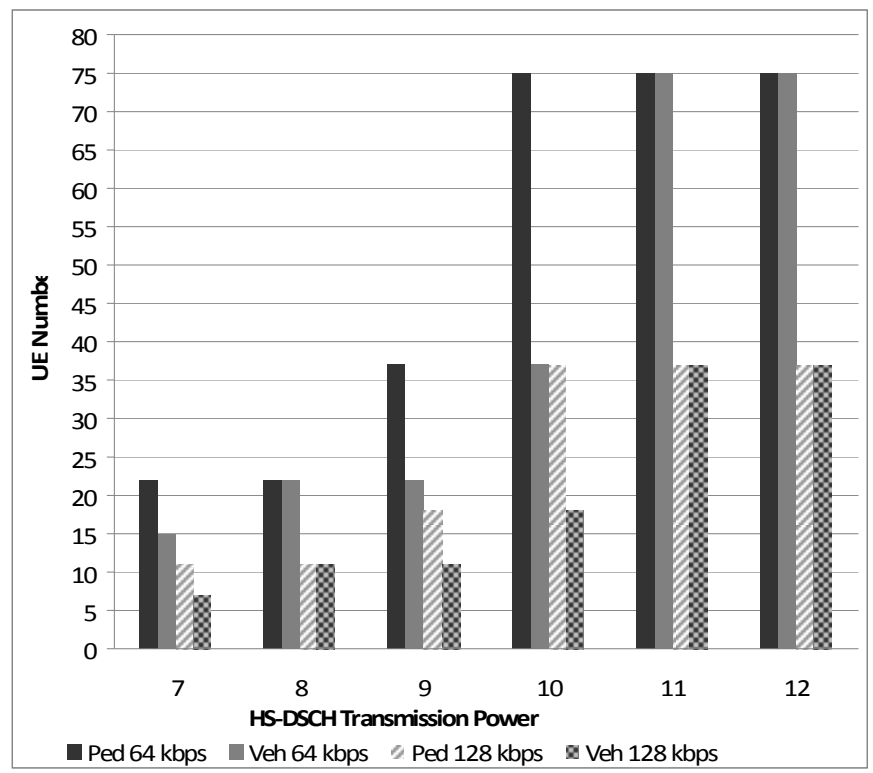

Figure 5 - Maximum UE Number considering radius up to 550 metres

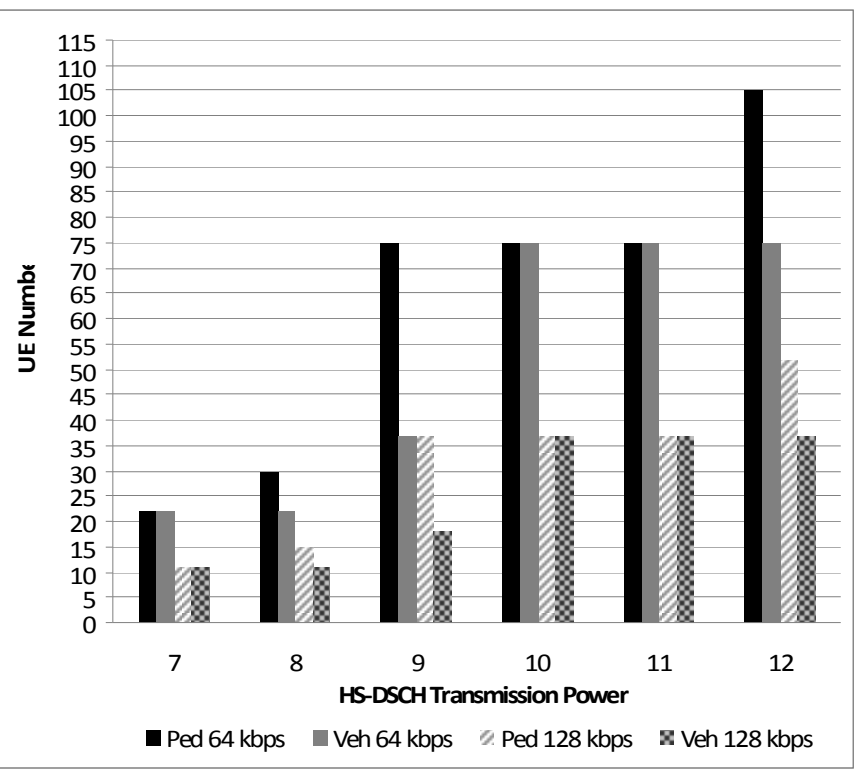

Figure 6 - Maximum UE Number considering radius up to 350 metres

The Data Rate is related to the Transport Block Size, indicating the transmitted packet size before entering the coding and modulation chain. While the Data Link Bit Rate quantifies the number of transmitted RLC Packets every TTI.

For instance, by referring to Table 3, it's worth noting that CQI values equal to 17 and 22 support the same number of users. In fact, the relevant Physical Bit Rates have the same values (4.800 kbps). But, as shown in Table 6, Data Rate and Data Link Bit Rate are different for such CQIs. In fact, a CQI equal to 17 corresponds to a Data Rate of $2094.5 \mathrm{kbps}$ that allows sending 12 RLC packets with a Data Link Bit Rate equal to $1920 \mathrm{kbps}$. While a CQI equal to 22 is equivalent to a Data Rate of $3584 \mathrm{kbps}$ that enables to transmit 21 RLC packets with a Data Link Bit Rate equal to 3360 kbps. Thus, a 
different amount of RLC packets can be transmitted with the same Physical Bit Rate depending on the radio channel condition, thanks to the AMC technique that allows to change coding and modulation every TTI. In particular, when a lower CQI value is available (i.e., CQI equal to 17 instead of 22), a higher signal robustness is given, but at the penalty of having a lower Data Link Bit Rate (i.e. 1920kbps and 3584 kbps respectively). This is due to the greater amount of redundancy, compared to the information bits that counterbalance the scarce channel quality [12].

TABLE 6 - MAPPING BETWEen CQI VALUE AND RLC PACKET SIZE

\begin{tabular}{|c|c|c|c|c|}
\hline CQI & $\begin{array}{l}\text { Transport } \\
\text { Block Size } \\
\text { (bits) }\end{array}$ & $\begin{array}{c}\text { Data Rate } \\
\text { (kbps) }\end{array}$ & $\begin{array}{l}\text { RLC Packets } \\
\text { Number }\end{array}$ & $\begin{array}{c}\text { Data Link } \\
\text { Bit Rate } \\
\text { (kbps) }\end{array}$ \\
\hline 1 & 137 & 68,5 & 0 & 0 \\
\hline 2 & 173 & 86,5 & 0 & 0 \\
\hline 3 & 233 & 116,5 & 0 & 0 \\
\hline 4 & 317 & 158,5 & 0 & 0 \\
\hline 5 & 377 & 188,5 & 1 & 160 \\
\hline 6 & 461 & 230,5 & 1 & 160 \\
\hline 7 & 650 & 325,5 & 1 & 160 \\
\hline 8 & 792 & 396 & 2 & 320 \\
\hline 9 & 931 & 465,5 & 2 & 320 \\
\hline 10 & 1262 & 631 & 3 & 480 \\
\hline 11 & 1483 & 741,5 & 4 & 640 \\
\hline 12 & 1742 & 871 & 5 & 800 \\
\hline 13 & 2279 & 1139,5 & 6 & 960 \\
\hline 14 & 2583 & 1291,5 & 7 & 1120 \\
\hline 15 & 3319 & 1659,5 & 9 & 1440 \\
\hline 16 & 3565 & 1782,5 & 10 & 1600 \\
\hline 17 & 4189 & 2094,5 & 12 & 1920 \\
\hline 18 & 4664 & 2332 & 13 & 2080 \\
\hline 19 & 5287 & 2643,5 & 15 & 2400 \\
\hline 20 & 5887 & 2943,5 & 17 & 2720 \\
\hline 21 & 6554 & 3277 & 19 & 3040 \\
\hline 22 & 7168 & 3584 & 21 & 3360 \\
\hline 23 & 9719 & 4859 & 28 & 4480 \\
\hline 24 & 11418 & 5709 & 33 & 5280 \\
\hline 25 & 14411 & 7205,5 & 42 & 6720 \\
\hline 26 & 17237 & 8774 & 52 & 8320 \\
\hline 27 & 21754 & 10877 & 64 & 10240 \\
\hline 28 & 23370 & 11685 & 69 & 11040 \\
\hline 29 & 24222 & 12111 & 72 & 11520 \\
\hline 30 & 25558 & 12779 & 76 & 12160 \\
\hline
\end{tabular}

\section{CONCLUSIONS}

The use of HS-DSCH can provide higher data rates and improve the performance of pre-existing UMTS channels for MBMS applications. In this paper, we evaluated the maximum number of users served by HS-DSCH, taking into account two different mobility models. The study has been conducted by considering different values of HS-DSCH assigned power and several cell radius coverage sizes. We highlighted how such parameters allow obtaining the SINR values that have to be guaranteed. These values influence the maximum number of users that can be served through HS-DSCH. We demonstrated that the propagation conditions specified by the ITU Pedestrian $A$ model always enables to serve a greater or equal number of users in comparison to the ones specified by the ITU Vehicular A model. Moreover, we illustrated the difference between Physical Bit Rate, Data Rate, and Data Link Bit Rate, by highlighting how several Data Rate and Data Link Bit Rate could be mapped into the same Physical Bit Rate, depending on the quality of the channel.

\section{REFERENCES}

[1] H. Holma, A. Toskala - WCDMA for UMTS - Radio Access for Third Generation Mobile Communications, 2004 John Wiley and Sons.

[2] H. Holma, A. Toskala - HSDPA/HSUPA for UMTS - High Speed Radio Access for Mobile Communications, 2006 John Wiley and Sons.

[3] 3GPP TR 23.846 V6.1.0 Technical Specification Group Services and System Aspects; Multimedia Broadcast/Multicast Service (MBMS); Architecture and functional description (Release 6).

[4] A. Alexiou, C. Bouras, V. Kokkinos, E. Rekkas - Efficient Delivery of MBMS Multicast Traffic over HSDPA (IEEE 2008).

[5] A. Raschellà, A. Umbert, G. Araniti, A. Iera, A. Molinaro - SINR-based Transport Channel Selection for MBMS Application (VTC 2009)

[6] 3GPP TS 25.101 V6.9.0 Technical Specification Group Radio Access Network; User Equipment (UE) radio transmission and reception (FDD) (Release 6).

[7] Guidelines For Evaluation Of Radio Transmission Technologies For Imt-2000, Recommendation ITU-R M.1225.

[8] IST-2003-507607 (B-BONE). Deliverable D2.5. Final results with combined enhancements of the air interface.

[9] 3GPP TS 25.211 V5.8.0 Technical Specification Group Radio Access Network; Physical channels and mapping of transport channels onto physical channels (FDD) (Release 5).

[10] J.-B. Landre, A. Saadani - Receive Diversity and LMMS Equalization Benefits for HSDPA: Realistic Network Throughputs, 18th Annual IEEE International Symposium on Personal, Indoor and Mobile Radio Communications (PIMRC'07).

[11] 3GPP TS 34108 V8.2.0 Generation Partnership Project; Technical Specification Group Radio Access Network; Common test environments for User Equipment (UE); Conformance testing (Release 8).

[12] T. E. Kolding, K. I. Pedersen, J. Wigard, F. Frederiksen, P. E. Mogensen, Nokia Networks - High Speed Downlink Packet Access (HSDPA): WCDMA Evolution. 